\title{
Özel Gereksinimli Çocuklarda Drama Modelleri ve Oyun
}

\author{
Pinar BAYHAN. Arzu YÜKSELEN**
}

Hacettepe Üniversitesi

\begin{abstract}
Özet
Drama, kendini ifade edebilmeyi, kendini ve başkalarını tanımayl, anlamayl, dinlemeyi, eleştirmeyi, yaratıcı hayal gücünü, kendine güveni, paylaşmayl, yardımlaşmayı ve empati kurmayı kapsayan bir bütündür. Eğitimde drama, bir iletişim kurma ve etkileşimde bulunma yöntemidir. Toplum yaşamını algılamada ve uyum sağlamada önemli bir rolü vardır. Çocuğun yakın çevresindeki olayları yaparak ve yaşayarak somut bir şekilde yaşantıya dönüş̧ürmesini sağlar. Normal gelişim gösteren çocuklarla ayn gelişimsel süreçleri izleyen özel gereksinimli çocukların eğitiminde de dramanın kullanılması ve bu yolla başta sosyal gelişim olmak üzere gelişimsel olarak desteklenmeleri önemlidir. Bu bağlamda bu çocuklara yönelik kullanılan farklı drama modellerinden yaratıcletkileyici model, görevler ve beceriler modeli ile kendini savunma modelinden söz etmek mümkündür. Engeli her ne olursa olsun özel gereksinimli çocukların eğitiminin bir diğer parçası da oyundur ve oyun drama ile iç içedir. Oyun yoluyla çocuk kendini ifade edebilme ve iletişim kurma firsatını elde eder. Özel gereksinimli çocuklardaki oyuna yönelik olarak burada simgesel oyun, sembolik oyun ve doğaçlama oyuna ait farklı örnekler sunulmaktadır.
\end{abstract}

Anahtar sözcükler: Özel gereksinimli çocuklar, drama modelleri, oyun.

\begin{abstract}
Drama is a whole which give you possibilities to express yourself; to know, understand, listen and criticize yourself and others; to promote creative imagination, self-confidence, and sharing and helping others and empathy skills. Drama in education is a communication and interaction method in addition to its important function in social perception and adjustment. It provides children a possibility to convert the events in his/her environment into real experiences by doing and experiencing. It is important to use drama method for the education of children with special need who follow the same developmental stages with normally developing children in order to support mainly their social development and other developmental areas. For this purpose, various drama models such as creative-effective model, duties and skills model and self defense model could be used for children with special needs. Play is another part of the children with special needs not depending on the type of their disabilities, and the play is closely related with drama. Children find a possibility to express themselves and to communicate by means of play. For the plays used for children with special needs, various examples of symbolic play and improvisational play were given here.
\end{abstract}

Keywords: Children with special needs, drama models, play.

-Prof. Dr., Hacettepe Üniversitesi Çocuk Gelişimi ve Eğitimi Bölümü, E-posta: pbayhan@hacettepe.edu.tr

${ }^{* *}$ Dr., Hacettepe Üniversitesi Çocuk Gelişimi ve Eğitimi Bölümü, E-posta: aipek@hacettepe.edu.tr 


\section{Giriș}

Dramadaki oyun ve doğaçlama çalışmaları çocuğun yaşına uygun tüm etkinlikler için bir hazırlık olmakta, çocuk çok erken yaştan itibaren karşılaşabileceği durumları oynayabilmektedir.

Günümüzde bilinen şudur ki, tüm çocuklar aynı gelişimsel süreçlerden benzer yollarla ve benzer sırayla ancak değişik yaşlarda ve değişik hızlarda geçmektedirler. Uygun gelişimsel destek verildiğinde birçok engelli çocuk umulanın çok üstünde performans gösterebilir. Bununla birlikte gelişim hızındaki yavaşlıktan dolayı engelli çocukların akranları ile oyun oynamalarında sorunlar yaşanabilir. Bu durum iletişim sorunları ile birleştiğinde diğer çocukların hoşlandığı oyunların içerdiği becerileri uygulama fırsatları daha az olacaktır. Dolayısıyla, gelişimsel yönden “...mış gibi yapma” oyunlarına katılmaya hazır olsa bile, kendiliğinden bu tarz oyunları oynayamayacak ve becerileri öğrenmek için yetişkin desteğine ihtiyaç duyacaktır (Öztürk, 2000).

Çocuk dramatik oyuna katılmadan önce bazı becerileri kazanmış olmalıdır. Bunların başında sosyal becerilerden içinde bulunduğu çevrede serbestçe dolaşabilme ve keşfedebilme becerisi gelmektedir. Ayrıca oyuncakları ve diğer nesneleri kullanabilme yetisini de gösterebilmelidir. Kendi adı söylendiğinde tepki verebilmeli, tanıdığı kişilerle karşılaştığında onları ayırt edebilmeli ve böylelikle benlik saygısının gelişmeye başladığı izlenimini uyandırmalıdır. Vücut kısımlarını ve işlevlerini tanıyabilmeli ve vücut hareketlerine yönelik basit yönergeleri yerine getirebilmelidir. Kendisinden istenileni anlayabilecek ve doğru tepkiler verebilecek düzeyde gelişimsel olgunluğa sahip olmalıdır. $\mathrm{Bu}$ özelliklere sahip olan engelli çocuklar “...mış gibi yapma” oyunlarına katılabilirler (Jennings, 1992).

Engelli çocuklara yönelik çok sayıda farklı drama modellerinden söz edilebilir. Bu bağlamda aşağıda bu çocuklara yönelik üç model üzerinde durulacaktır (Cattanach, 1992).

\section{Yaratıcı- Etkileyici Model}

Özel gereksinimli çocuklar için dramanın en önemli modelidir. Bu modelin odak noktası, dramadaki grubun ya da bireylerin kendi yaratıcı potansiyellerini keşfetmeleri ve olumlu olan taraflarına odaklanmalarını sağlamaktadır. Bu modelde oyun içinde keşifler olduğu gibi hem sözlü hem de sözlü olmayan iletişimin örnekleri bulunmaktadır.

Grupla beraber oynayarak sosyal becerileri geliştirme ve oynarken grubun diğer üyeleri ile iletişim kurma ihtiyacını karşılama, yerine getirme söz konusudur.

Uygulama sırasında oyunun gelişimsel basamaklarında simgesel oyundan projektife sembolik oyundan taklidi oyuna doğru bir geçiş yaşanır. Bu çalışma yöntemi bireyin güvenini arttırmakta, bu durum da grubun eğitim gücüne yansımaktadır. Özellikle dramada sınırlı deneyime sahip insanlar için kendilerine saygılarının artmasını sağlayıcı bir modeldir. 
Grubun içindeki kapasiteye dayalı olarak becerilerin gelişimini sağlamak her zaman önemlidir. Yaratıcı etkileyici model yalnızca karmaşık rolleri tanımlama yeteneğine ve belirli bir limitle çok başarılı olabilmeye ya da sözsüz iletişim kurabilmeye dayanmaz. Bu modelde grup güven ve beceriler kazanırken rol yapabilme yeteneği de geliştirebilir. Bir çok grup yaratıcı oyunun deneyiminden ve çocukluk döneminin rol alma özgürlüğünü yeniden keşfetme firsatlarının verilmesinden çok hoşlanmaktadır. Risk altındaki gruplarla bu tarz çalışmalarda birçok hareket ve ses çalışması yapılarak bireysel deneyimlerini bütün grupla paylaşabilirler. Ancak belli bir süreden sonra bireyler kendi vücutlarını keşfederek artık daha rahat uygulama yapılabilir duruma gelebilirler. Zihinsel engelli çocukların dil gelişimleri oldukça zayıf olan gruplarda bile çıkardıkları sesler konuşma öncesi babıldama iken gittikçe çalışma boyunca şarkı söylermiş gibi hafif karmaşık ve ritmik şekil almaktadır. Bu çocuklarla iletişimde kullanılan kelimelerin karmaşık olmamasına dikkat edilmeli ve çocukları memnun edecek şekilde uygun görülen hareketler ve sesler de kapasiteleri ölçüsünde yapılmalıdır. Zihinsel engelli dil gelişimi zayıf olan çocuklarla hareketler zemin üzerinde yuvarlanma ve itmeyi içermektedir. Burada amaç basit düzeyde de olsa çevreyle iletişim kurmalarını firsat verirken bazı hareketleri ve sesleri de bir araya getirmelerini sağlamaktır.

\section{Görevler ve Beceriler Modeli}

$\mathrm{Bu}$ model genel sosyal becerileri içermektedir. Dramanın kullanımı ile sosyal etkileşimi öğrenmek amaçlanmaktadır. Grubun şimdiki değerleri üzerine amaç edinilmiş öğrenme yöntemi heyecan verici olabilir.

Bazen diyabet gibi belirli zorluğu olan grupla deneyimleri paylaşmak ve hastalığın doğurduğu hisleri paylaşmak gibi durumlar da drama öğrenmenin etkili bir yolu olabilmektedir. Diyabetik yetişkinlerin olduğu grupla yapılan çalışmalarda oturuma drama basamaklarıyla başlanabilir. Grup tarafından konu belirlenip diyabetik olmanın ve zorluklarının ne tür duygular yarattığı, aynı zamanda diyabetik olan gencin çevresinden ne beklediğine dair mesajlar alınan rollerle iletilmiş olabilir. Sonunda hangi konu seçilirse seçilsin bu tip kronik hastalıkları olan çocuklarda gelinen nokta hastalıkla ilgili duygu, düşünceler ve gereklilikler üzerinde toplanmaktadır. Kronik hastalığ 1 ya da özel gereksinimi olan çocuklarla yapılan dramada yaşanılan problemin içinden çıkmak için problem durumunu düzenleme, iyileştirme yolları ile ilgili planlamalarını ve duygularını yansıttıkları görülmektedir. Genellikle dramada olası durumlar ortaya konarak kişinin kendini başkalarının yerine koyup, onların ne hissettiğini algılamaya çalışarak iletişim kurmaya çalışması esastır.

Dramada önemli olan hislerini tanıyarak başlamaları ve sessiz kaldıkları küçük düşürüldükleri ve incindikleri durumlara dayanmak zorunda olmamalarıdır. 
Dramaya belli bir durum karşısında duyguları tanıma amacıyla başlanır. Bu duyguları ortaya koymak için oyunlar geliştirilir ve nasıl çözülebileceğine ilişkin çözüm yolu bulunur.

\section{Kendini Savunma Modeli}

Özel gereksinimli bireylerin kendilerinin farkında olmalarına yönelik becerileri gelişirse ve aynı inanca, fikre, amaca sahip insanlarla paylaşımlarda bulunurlarsa, içinde bulundukları grupta kendilerini savunmayı keşfederlerse, hissettikleri ya da keşfettikleri baskıyı tarif edebilmekte ve buna karşın kendilerini savunabilmektedirler.

Augusto Boal'in (1979) Mazlum'un Tiyatrosu (The Theatre of Opressed)'nda olduğu gibi önemli bir konuda kaygı duyan grubun kendini ifade etme, güç durumlarla başa çıkma ve kendini avutmayı öğrenmede tiyatro tekniklerini keşfetmesi ve kullanması sağlanabilir. Onun çalışması drama, tiyatro ve psikoterapi arasındaki konuları belirlemektedir. Boal'e göre (1979) kişinin hissettiklerini sergilemesi gerçek hayattan çıkan ancak estetik olan sanat çalışmalarıdır. Böylece baskının neden olduğu iki farklı dünyanın özerkliği ortaya çıkmaktadır. Biri gerçek dünya diğer de kendi yarattıkları hayali dünyadır (Akt.: Cattanach, 1992).

Uygulamalarda hayallerde hissedilen baskı değiştirilebilir. Hayalimizde yarattığımız ve canlandırdığımız şekilleri ve görüntüyü uygulama sırasında yaşadığımız duygu ve durumlara göre değiştirebiliriz. Buradan hareketle bunu temel alarak gerçek yaşamda da değiştirmeye çaba harcayabiliriz.

\section{Özel Çocuklar ve Dramada Oyun}

Drama, normal gelişim gösteren çocuklarda olduğu kadar özel eğitime gereksinimi olan çocukların gelişiminde de oldukça önemlidir. Özellikle özel eğitime gereksinimi olan çocukların öğrenme süreçlerinde ve kendilerini ifade etmelerinde normal gelişim gösteren çocuklardan daha yararlı olmaktadır. Özel eğitime gereksinimi olan çocukların genel olarak dikkat süreleri kısadır, zaman zaman disiplin problemleri bulunmaktadır. $\mathrm{Bu}$ durumların giderilmesi ve bu çocukların gelişimlerini desteklemek için onların sanat, müzik ve özellikle de drama ile ilgilenmelerini sağlamak yararlı olacaktır. Ancak bu oyunlar sırasında özel eğitime gereksinimi olan çocuklar gerçeğe daha yakın tutulmak zorundadırlar. Oyunlarda seçilen konuların canlandırılmasında parmak oyunları, kukla, dans, maske vb. kullanılması yararlı olabilir (Bayhan, 1995).

Özel eğitime gereksinimi olan çocukların özelliklerinden biri de hayal güçlerinin ve yaratıcı düşüncelerinin yavaş olmasıdır. Dramada özel eğitime gereksinimi olan çocuktan geri iletişim beklenenden daha sonra gerçekleşebilir. Drama uygulamalarında özel eğitime gereksinim duyan 
çocukların diğer çocuklardan daha çok yardıma, güdülenmeye, daha fazla ve sık tekrarlara gereksinimi olabilir (McClintock, 1984).

Özel eğitime gereksinimi olan çocuklar da normal gelişim gösteren çocuklarda olduğu gibi oynarken oynadıkları rolü yaşarlar. Oyun sırasında duygularını ortaya koyarlar ve kendilerini ifade etme fırsatı yakalarlar (McClintock, 1984).

Özel eğitime gereksinimi olan çocukların eğitiminde dramanın kullanılması, bu çocukların kendilerine güven duymayı öğrenmesini ve bir gruba dahil olmanın getirdiği tatmini yaşamasını sağlayacaktır. Ayrıca hikayeler çocukların drama yoluyla hayal güçleri gelişecek, yeni deneyimlere karşı hazırlıklı olmayı öğrenebilecek ve sözel iletişim kurmak için bir alt yap1 oluşturabileceklerdir. "Dinleme ve Gözlem Yapma” becerileri gelişerek dikkatlerini daha uzun süre toplayabileceklerdir

Özel gereksinimli çocuklarda dramatizasyon için seçilen hikaye basit, açıkça anlaşılır ve ilgi çekici olmalıdır. Çocukların ilgi alanlarını genişletirken tanımlayacakları ve ifade edebilecekleri yeni kelimeler içeren değişik hikayelere yer verilmelidir. Ayrıca özel eğitime gereksinimi olan çocuğun yaşamı anlamasına yönelik amaçlar taşımalıdır. Bütün drama çalışmalarında çocuğun etkinliklere en iyi şekilde uyum sağlayabilmesi için gelişim düzeyinin, ilgi ve ihtiyaçlarının göz önüne alınması gerektiği unutulmamalıdır (Gönen, Şahin, Yükselen, Tanju ve Celep, 2006).

Özel gereksinimli grubuyla oyun oynamak, rutin davranışları kazanmalarına neden olabilmektedir. Bazı özel gereksinimli gruplar örneğin fiziksel engeli olan ya da öğrenme güçlüğü çekenler kendi gelişimsel seviyelerine göre oynayabilirler. Ancak liderin yaratıcılığı yaratıcı alternatifler sunabilir. Özel gereksinimli çocuklar ve yetişkinler için kendi olanaklarını keşfetmekte oyun güvenli bir yoldur (Polloway \& Patton, 1993).

\section{Simgesel Oyun}

Duyumsal hafıza ve farkındalık ile iletişim kurmanın bir yolu simgesel oyundur ve belki de oyunun erken bebeklik deneyimlerini hatırlatır. Simgesel oyunlarda gerçek nesneye ulaşılamadığı zaman onu zihninde canlandırarak varmış gibi davranabilir ve onun yerine başka bir nesne koyabilir. $\mathrm{Bu}$ da dramanın dilini öğrenmenin başlangıcıdır. Boal (1979) "tiyatro dili sözlü dili içerir ama asıl önemli olan hayal, beden dili ve sembol” demektedir (Akt.: Brewer, 1995).

Erken çocukluğun en büyük görevi doğumdan itibaren değişmektedir. Bunlar için de birçok hareket gelişimini içeren durumlar vardır. Özellikle emekleme, yürüme, koşma, merdiven inip çıkma. Belki de insan olmak için yer değiştiren daha ilkel mücadelede bulunmanın yolundan geçen herkes için bu durumlar kolay ama bedeniyle durmadan mücadele eden özel gereksinimliler için güçtür. 
Özel gereksinimli çocuklarla drama çalışmalarında buradan hareketle;

1. Drama odasının çevresini keşfetmekle başlanabilir. İnsanoğlu daha yürümeden çevresini keşfetmektedir.

2. Duyularını uyarma dolayısıyla şimdiki çevresini olabildiğince sahip olduğu dokunma, tatma, koklama, görme, duyma ile beğenme.

3. Hareket edebilme yetileriyle dünyayı keşfetme, gibi uygulamalara yer verilmelidir.

$\mathrm{Bu}$ tip duygularla ve rahatlamayla yapılan keşifler birçok özel gereksinimli grup için başlangıç olabilir. Hareket etmekte güçlük çekenlerde grubun kapasitesine dikkat edilmelidir.

Uygulamalarda hareketin başlangıcından bedenini çocukların öğrendiği gibi benzer süreçlerden geçip, benzer eylemlerde bulunarak keşfedebilmek; yuvarlanma, uzuvlarını olabildiğince uzatma ya da bükülme, kayma kıvrılma çok hareketlenme, düşme ve yuvarlanma gibi durumları kullanmak gereklidir.

Çok önemli olan bir nokta şudur ki liderler kendi fikir ve yöntemlerini çalışmada empoze etmemelidir. Çünkü drama grubu kendilerini harekete geçirecek bir takım oyunlardan oluşan sinerjiyi kendileri yaratabileceklerdir.

Bedenle ilgili dünyanın keşfinden fiziksel benliğe doğru haberdar olma durumunda yaratıcılık gelişebilir. Basit rahatlamadan ve hareketli oyundan grubun konulara odaklanması geliştirilebilir. Bu tür konular başlangıçta birkaç çeşit grupla bağlantı kurularak çalışılabilir. Eğer grup duyguların beden diliyle ifade edilmesi ve onların diğerleriyle nasıl iletişim kuracağı üzerine yapılandırılmışsa ya da bedensel istismara uğramış bireylerden oluşmuş gruplar ile çalışılacaksa vücut sınırları üzerine dokunma oyunu oynanabilir.

\section{Örnek Uygulama}

"Kapanma pozisyonu alacă̆ın rahat bir zemin bul

\section{Gözlerini kapat ve açma}

Yumuşak bir ipek gibi kozayla sarılı olduğunu seni çok iyi koruyan bir kabuğunun olduğunu hayal et. Koza içindeki yaşamı keşfet. Ne büyüklükte bir cevrede olduğunu keşfet. Şimdi yavaşça kozandan çık. Meydana çıktığında nasıl hissettiğinden haberdar ol. Meydana çıktı̆̆ında bedenini germeye başla. Gözlerini aç ve etrafindaki insanlara bak. Islak ve güvenli kozanda yalnız olmayı keşfettin. Gözlerini aç ve dışarldaki dünyanın görünüşüne bak”.

Bu çalı̧̧ma grup üyelerinin diğer bireylerle ilişki kurmasında bir yoldur. Pekala arkadaş edinmek için ne yapmalisin? 
Insanlarla nasıl konuşursun?

Bunlar özel gereksinimli insanlardan gelen sabit sorulardır. "Sadece gözlerini aç, insanların gözünün içine bak. Odadaki insanlara sadece gülümse." gibi uygulamalarla başlangıç yapılabilir.

$\mathrm{Bu}$ uygulamalarla fiziksel olarak hislerimiz dışarıdaki dünya hakkında bize ne anlatıyor oyununu keşfetmeye başlayabiliriz. Dışarıdaki dünyayı bize hissettirecek semboller ve metaforlar kullanabiliriz. $\mathrm{Bu}$, sembolik oyunun başlangıcıdır.

\section{Sembolik Oyun}

Çocuk, erken çocukluk döneminde "ben neyim" ve "ne değilim” farkındalığına sembolik oyunla varır. $\mathrm{Bu}$, dünyadaki nesnelerin ve ilişkilerin ilk başlangıcıdır. Çocukların aslında sembolik oyun yolu ile hikaye oluşturmaları ve olayları geliştirerek kendi dünyalarını ifade etmeleri dramatik oyundur (Brewer, 1995).

Nesnelerin sembolik kullanımı, nesneleri kavrayabilen ama hareket kısıtlılığı olan grupla özellikle uygulanması gereken uygulamalar olarak önem taşır (Ainsworth \& Baker, 2004).

Örnek 1:

Herkes daire olacak şekilde otursun. Bir kişi kalem alarak onu belirli şekilde kullanarak başlar. Kalemin herhangi bir şey olabileceğini gösterir. Birey kalemi başka bir nesne olarak kullanır (Örneğin, tarak). Grup kalemin ne olabileceğini tahmin etmelidir. Ardından kalem diğer kişiye geçirilir. Bu kişi kalemi başka bir şekilde kullanmalıdır. Kalem herkesin elinden birkaç defa geçmelidir. Bu oyun nesnelerin sembolik olanaklarıyla grubun iletişim kurmasını sağlar.

Nesnelerin hayali kullanımı çocukların sembolik anlayışının gelişim yoludur. Sembolik oyunu geliştiren dramalara "rol alma" ile başlanabilir..

\section{Örnek 2:}

Lider bebek, plastik hayvanlar ve ev eşyalarını ortaya koyar. Bütün nesneler mekanın temelidir. Her birey bir bebek ya da hayvan seçer ve büyük bir kağıda çizmek için onunla ilgili, yaşadığı yerle ilgili sorular sorar. Çizme bittikten sonra nesneler çevresine yerleştirilir. Her bir kişi böylece dünyayı tanımlar. Diğer basamak yaratılan her bir dünya üzerine hikaye oluşturma ve sahneleme olabilir.

\section{Doğaçlama Oyun}

Dramada, sembolik oyun deneyiminin sürecinde doğaçlama oyun diğer basamak olabilir. Kendi vücudumuzun ve nesnelerin sembolik kullanımlarının duyusal keşfini hikayelerle tecrübe etmeye başlayabiliriz. Drama nesneleri ve deneyimleri değiştirme kapasitesine sahiptir. Bu, dramanın gücüdür. 
Doğaçlama bu gücün odak noktasıdır. Hareket "anlatma, göster" mesajına odaklanmıştır. Lider için drama gruplarının bir şey yapma üzerine konuşmakta saplanıp kalmaması önemlidir. Lider, grubun becerisinin ne olduğunu bilmeli ve grubu oynamaya teşvik edebilmelidir. Lider, grubun hareketleri güvenli şekilde yapmalarına yardım etmeli ve her grup üyesine yeterli güveni sağlamalıdır (Ainsworth, Baker, 2004).

Örnek 1:

Her bir kişi farklı nesne bulmak zorunda. Nesneleri göster. Nesnelerin kendi yaşamını düşün. Nesnelerin sahibinin nesneleri nasıl kullanması gerektiği ile ilgili hikaye doğaçlattır. Grupla hikayeyi paylaş.

\section{Örnek 2:}

Bu odayl park olarak düşün. Sahneyi kur. Parkta bank, havuz, çiçekler, yüzen ördekler, park kurallarının yazdı̆̆ levha ve dondurmacı var. Gruptan hoşlandı̆̆ın herhangi biri ya da istersen bir hayvan parka seninle gelebilir. Parktaki diğer insanlarla tanıs ya da tanışma. Ördeklere yem ver ya da yürü. Bankta otur ne istersen seç. Ĕ̆er bir köpeksen parkın etrafinda dolaş. Ama sadece 4 kişi aynı zamanda bu parkta olabilir. Beşinci bir insan gelirse dördünüzden biri gitmeli. Kaç tane hayvan ya da insan oradan ayrldd ona bak.

\section{Örnek 3:}

Oyuna başlamanın diğer yolu çiftlerle çallşmak eş olmak. Gruptan biri bir mekanın ambulans istasyonu ya da telefon kulübesi gibi bir isimle adlandırtr. Diğeri oyunu o mekanla alakalı olan bir nesne olur. Ardından çift kısa bir sahne canlandırır. Biri insan diğeri nesne olarak oynar.

Lider, grubun belli temaları veya senaryoları oynamaları için firsatlar sağlayabilir. Örneğin, ulaşımda emniyeti sağlamayı öğrenen grup üyeleri emniyet kemerinin bağlanmasının önemiyle ilgili bir senaryoyu oynayabilirler. Grubun mevcut becerilerine bağlı olarak oyun hazırlıksız oynanabilir veya önceden planlama yapılabilir. Lider ve grup karakterlerin sayılarını ve tiplerini belirlemek gibi bazı parametreleri düzenleyebilirler. Benzer şekilde bir senaryonun başlangıç bölümü verilip sonrasının grup tarafindan tamamlanması istenebilir. Örneğin lider "Küçük ayı bütün gece hiç uyuyamamış” der ve daha sonra gruba ayının neden uyuyamadığını sorar. Grup bir sebep üzerinde hem fikir olur ya da liderin yönlendirmesiyle bir sebep üzerinde odaklanır ve sonrasında canlandırma aşamasına geçilir. Özellikle hafif derecede engelli bireylerle yapılan dramatik oyun ve doğaçlama uygulamalarında, grubu doğaçlama oyuna güdülemede şunlar da yapılabilir (Ainsworth \& Baker, 2004):

-Oyun alanına bir kutu içine farklı meslek gruplarını temsil eden yetişkin giysileri koyarak grubun bu giysileri giyerek rol oynamaya yönlendirilmesi sağlanabilir. 
-Bir mikrofon vererek grup üyelerinin komedyen şarkıcı veya dansçı olarak rol almaları sağlanabilir.

Grubun eşli veya küçük gruplar halinde gerçek veya hayali kişilerle karşılaştıklarını düşünerek sözel diyaloglarla taklit etmeleri sağlanabilir. Lider ve grup üyeleri bu karşılaşma ile ilgili parametreleri birlikte belirleyebilirler.

\section{Kaynaklar}

Ainsworth, P ve Baker, P. (2004). Understanding Mental Retardation. Mississipi, USA:University Press of Mississipi Jakson.

Bayhan. P. (1995). Zihinsel engelli çocuklarda drama. A.Ü. Eğitim Bilimleri Fakültesi Özel Eğitim Dergisi, Kasım, 2(1), 46-48.

Brewer, J.A. (1995). Introduction to Early Childhood Education Preschool Through Primary Grades. USA: Allyn and Bacon, Second Edition.

Cattanach, A. (1992). Drama People with Special Needs . New York, USA:A\&C Black Publishers.

Gönen, M., Şahin, S., Yükselen, A., Tanju, E. ve Celep, S. (2006). Özel Eğitime Gereksinimi Olan Çocuklar İçin Yaratıcı Drama. 1. Baskı, Epsilon Yayıncılık Hiz. Tic. San. Ltd. Şti. , İstanbul.

Jennings, S. (1992). Creative Therapy. Pitman Publishing, London.

Polloway, E.A., Patton J.R. (1993). Strategies for Teaching Students with Mild to Severe Mental Retardation . Merrill, an imprint of Printice Hall, Upper Saddle River, New Jersey Columbus, Ohio.

McClintock, A.B. (1984). What is Educational Drama? Why Do Drama?, Drama for Mentally Handicapped Children. London: A Condor Book Souvenir Pres (E\&A) Ltd.

Öztürk, A. (Ed.) (2000). Çocukta Yaratıcılık ve Drama. Anadolu Üniversitesi Yayınları, Eskişehir. 


\title{
Summary
}

\section{Drama Models and Play on Special Needs Children}

\section{PInar BAYHAN. Arzu YÜKSELEN**}

\author{
Hacettepe University
}

It is an undeniable reality that drama has an important place in the education of the children with or without special needs. In this context, various drama models are considered for these two groups of children. Three models are considered for children with special needs:

1. Creative-Effective Model: It is the most important model for the children with special needs. It gives individuals a possibility to discover their creative performances and to be concentrated on them. This model does not depends on only the ability to describe complex roles and the base of nonverbal communication. Group members develop their role play skills while they gain self-confidence and other skills. Children like to have creative play experiences and opportunities to discover a freedom of role taking.

2. Model of Duties and Skills: It is a model including general social skills. It aims to teach social skills by using drama. With a group of individuals with a specific disease, such as diabetic individual, it could be an effective way to teach drama by sharing emotions and experiences. Sessions with such a group of adults may be started with the steps of drama. With the children with chronic illness, the main goal is to focus on emotions, thoughts and requirements about the illness regardless of the selected topic.

For the drama the main point is to have children be familiar with their feelings and to realize that they dont have to stand for the situations in which they are silent and be injured.

3. Model of Self-Defense: If the individuals with special needs have a chance to share their feelings with similar others and to discover ways to defend themselves they could describe the pressures they feel and defend themselves. Pressure in the imagination of an individual could be changed by means of the exercises of this model. By this way they could try to change real pressures.

\section{Children with Special Needs and Play in Drama}

Groups of children with a specific special need for example children with physical disabilities could play plays appropriate to their developmental levels and characteristics. But the leader may also present

-Prof. Dr., Hacettepe University, Child Development and Education Department, E-mail: pbayhan@hacettepe.edu.tr

${ }^{* *}$ Dr., Hacettepe University, Child Development and Education Department,E-mail: aipek@hacettepe.edu.tr 
different alternatives. Play is the most reliable way for an individual to discover his/her own opportunities.

Imaginative Play: Imaginative play is a way to communicate by means of sensual memory and awareness. The main purpose of such a play is body sensitivity which is the starting point of drama.

In a drama application for children with special needs, a child

1. discovers the surrounding of the drama place;

2. gets familiar with the his/her environment by means of such sensory stimulation as touching, smelling, tasting and seeing;

3. discovers the world by means of movement ability.

Discoveries with such sensations and relaxations may be a starting point for the individuals with special needs. Here it is an important point that the leader should not try to impose his/her ideas and methods to the group members. The group could create its own synergy in itself by means of play.

Symbolic Play: In early childhood, a child could realize the questions "what am I" and "what ain't I" by means of symbolic play. Children develop stories and express their own worlds by using symbolic plays. This is called as dramatic play.

Improvisation: We could discover symbolic use of our body and objects through stories. Drama has an significant power with its capacity to change objects and experiences. Improvisation is the focus of this power. In a drama session, a leader may not insist on only talking but could encourage the group to play. 
